\title{
THE CROSS-CULTURAL APPLICATION OF THE SOCIAL AXIOMS SURVEY IN THe South African POLICE SERVICE
}

\author{
ADI BARNARD \\ SEBASTIAAN ROTHMANN \\ WorkWell, Research Unit for People, Policy and Performance \\ North-West University \\ South Africa \\ DEON MEIRING \\ Department of Industrial Psychology \\ Stellenbosch University \\ South Africa \\ Correspondence to: Sebastiaan Rothmann \\ e-mail: ian@ianrothmann.com
}

\begin{abstract}
The objectives of this study were to investigate the replicability, construct equivalence, item bias and reliability of the Social Axioms Survey (SAS) in the South African Police Service (SAPS). A crosssectional survey design was used. The participants consisted of applicants who had applied for jobs in the SAPS ( $\mathrm{N}=1535)$, and the SAS was administered to them. An exploratory factor analysis utilising target rotation applied to all 60 items of the SAS revealed four interpretable factors (Social Cynicism, Reward for Application, Fate Control, and Spirituality/Religiosity). Values of Tucker's phi higher than 0,90 were found for seven language groups (Zulu, Sotho, Tswana, Swati, Tsonga, Venda and Pedi). Analyses of variance found that item bias was not a major disturbance. Unacceptable alpha values were found for some of the scales of the SAS.
\end{abstract}

Keywords: Social axioms, equivalence, validity, reliability, item bias

Researchers have extensively examined the concept of culture through values (Singelis, Hubbard, Her \& An, 2003). Culture has traditionally been defined in terms of values (Bond, Leung, $\mathrm{Au}$, Tong \& Chemonges-Nielson, 2004), and the attempts of social scientists to incorporate culturally distinctive values into measurements have resulted in the mapping of the value universe (Bond et al., 2004; Leung \& Bond, 2004). This enabled comparisons to be made of the value profile of representative persons socialised into different cultures (Leung \& Bond, 2004). Research also provided substantial evidence that the theory of basic human values applies across a wide range of cultures (Schwartz, Melech, Lehmann, Burgess, Harris \& Owens, 2001). Rokeach (1973) went as far as arguing that the value concept may be able to unify the apparently diverse interests of all the sciences concerned with human behaviour. Considering the South African situation, Mbigi (1993) stipulated that diverse values and attitudes may be the cause of conflict and stress between different culture groups. The value system, attitude and interaction of groups in multicultural communities can (and do) differ (Brislin, 1994; Triandis, 1994), resulting in cultural diversity.

Values theory has the following main elements: values are beliefs; values are a motivational construct; values transcend specific actions and situations; values guide the selection or evaluation of actions, policies, people and events; and values are ordered by importance relative to one another (Schwartz, 1992, 1994b; Schwartz \& Bilsky, 1990). The values perspective has been influential in defining the ways in which researchers compare cultures and explain differences in social behaviour (e.g., Kluckhohn \& Strodtbeck, 1961; Lonner \& Malpass, 1994; Rokeach, 1973; Schwartz, 1994a).

According to Leung, Bond, Reimel de Carrasquel, Munoz, Hernandez, Murakami (2002) and Bond, Leung, Au, Tong, Reimel de Carrasquel, Murakami et al. (2004), value dimensions have predominantly been the construct used to guide crosscultural research, and these have ensured valuable progress (e.g., Hofstede, 1980; Schwartz, 1992). For example, by using theoretical considerations and the measures they suggest, Schwartz (1992) discovered a pan-cultural typology of values, at the individual level, by following a functionalist approach. However, attempts to predict behaviour based on an individual's value priorities have often yielded unsatisfactory results. Despite this predictive weakness, values are regularly deployed to account for cross-cultural differences in behaviour (Bond et al., 2004). Values may therefore help to understand a culture, but they often have little to do with actual concrete, everyday behaviours (Kurman \& Ronen-Eilon, 2004).

As a result, there is a need for additional dimensions by means of which we can identify cultures and understand cultural variations (Singelis et al., 2003). Because the structure of a value is fairly similar to that of a belief, and values assume the form of " $A$ is good/desirable/important" (thus, $A$ is a value and its importance is determined by the importance or desirability that people attach to it), certain researchers have actually regarded a value as an evaluative belief (Leung \& Bond, 2004; Leung et al., 2002).

Lonner and Malpass (1994) have argued that values are general beliefs about desirable or undesirable ways of behaving and about desirable or undesirable goals or end states. Kurman and Ronen-Eilon (2004) argue that values describe endorsed endpoints, but not how these endpoints should be achieved. The linkages among constructs that are orientated toward how to achieve these endpoints (thus, mutual respect helps maintain basic human rights) are considered to be social beliefs.

Beliefs are key concepts in social sciences such as psychology, anthropology and political science. Probably the most familiar work in this regard is social representations theory (Leung \& Bond, 2004). Social representations theory, however, has been highly criticised for its vagueness, and especially for the poor construction of its concepts (e.g., Jahoda, 1988; Markus \& Plaut, 2001). In addition, lay beliefs have been studied in many 
domains for more than three decades, and the root of this work is often traced back to Heider's (1958) simplistic analysis of actions (Leung \& Bond, 2004). Kelly (1963) added the notion of the personal construct, which people use to perceive and interpret events and to take a course of action, while Furnham (1988) provides an overview of lay theories. Many more exciting findings of structures underlying lay beliefs have been documented in domains that have interested researchers, but no attempt has been made to search for a basic structure of beliefs that is domain general (Leung \& Bond, 2004). Independent but related to the study of lay theories was the development of processes underlying the formation and change of beliefs. Festinger's (1957) work on cognitive dissonance pioneered the research on process models of beliefs. Beliefs studied in this tradition have been domain specific, and once again not intended to discover a general structure of beliefs (Leung \& Bond, 2004). A review of the major research on beliefs has therefore made it clear that the concept of belief is a prominent construct in psychology, and also that significant discoveries have been made about the content of beliefs in different domains and about their underlying psychological processes. One cannot help to observe, however, that findings in these diverse areas are typically tied to a particular context and, when referring back to the work on beliefs in social representations and lay theories it is evident that a theoretical scheme for organising beliefs into a coherent structure is needed (Leung \& Bond, 2004).

\section{Beliefs}

People need assumptions on how their social worlds function. These assumptions, often expressed as beliefs, are known as implicit or lay theories. Although researchers have identified structures underlying lay beliefs in domains that interest them, no attempt has been made to search for and develop a contextfree structure of lay beliefs. In addition, beliefs are social in nature (e.g., patriotism, security, and siege), and are therefore widely shared in social groups (Chen, Bond \& Cheung, 2006), such as cultures. Shared beliefs reflect how people construct their social world and seek the meaning of and to understand social realities, which are context specific (Leung \& Bond, 2004).

Given that beliefs are the key components of attitudes, process models of beliefs have appeared along with process models of attitudes. Subsequently, the most well-known research on the psychological processes underlying beliefs is probably that exploring the self-fulfilling prophecy. However, beliefs studied in process models tend to be textured and domain specific and, as a result, the discovery of a context-free structure of beliefs has not been a goal of this research (Leung \& Bond, 2004). Furthermore, beliefs have been extensively used as individual differences variables (Chen et al., 2006) to explain and predict social behaviour. In this tradition, belief scales have been developed and their usefulness demonstrated through significant relationships with a variety of variables (Leung \& Bond, 2004)

Individual beliefs about human nature have shown to relate to various interpersonal behaviours. While belief items are found in many scales in the literature on individual differences, they are often mixed with items that tap values or behaviours. This merging creates theoretical ambiguity and imprecision in model development (Leung \& Bond, 2004). According to Leung and Bond (1989), analysis at the individual level (e.g., Schwartz, 1992) should not be confused, however, with that at the cultural level (e.g., Hofstede, 1980). Consequently, scales that are based entirely on beliefs are rare (Leung \& Bond, 2004).

\section{Social axioms}

Beliefs, unlike values, vary in specificity (Leung et al., 2002), and some beliefs are classified as general and may be viewed as generalised expectancies (Bond et al., 2004; Kurman \& Ronen-Eilon, 2004; Leung et al., 2002), while other beliefs are anchored in a context, defined by actors involved and tied to a particular setting in a given time period. Specific beliefs, on the other hand, are only applicable to a narrow range of situations and actors. In contrast, general beliefs are pitched at a high level of abstraction, are context free and are related to a wide spectrum of social behaviours across diverse contexts, actors, targets and time periods. These general beliefs function like axioms in mathematics, in the sense that these beliefs are basic premises that people endorse and rely on to guide their actions (Leung \& Bond, 2004; Leung et al., 2002). Hence the label social axiom is used, as these beliefs are axiomatic in that they are often assumed to be true as a result of personal experience and socialisation (Leung \& Bond, 2004; Singelis et al., 2003), but not as a result of scientific validation (Leung et al., 2002). Social axioms have therefore been proposed as an additional framework to complement the values perspective (Singelis et al., 2003).

Bem (1970) defines a belief as a perceived relationship that exists between two things or between something and a characteristic of it. Bar-Tal (1990, p. 14) has defined a belief as "[a] proposition to which a person attributes at least a minimal degree of confidence. A proposition, as a statement about an object(s) or relations between objects/or attributes, can be of any content". Based on these definitions and various other definitions of beliefs, social axioms have been defined as "generalized beliefs about oneself, the social and physical environment, or the spiritual world, and are in the form of an assertion about the relationship between two entities or concepts" (Leung et al., 2002, p. 289).

The definition of social axioms implies that the structure of $A$ is related to $B$, where $A$ and $B$ can be any entities (Bond et al., 2004; Leung \& Bond, 2004; Leung et al., 2002). A social axiom proposes a basic premise in the form of an assertion, in which a relationship between two entities or concepts is formed (Singelis et al., 2003). The relationship between them may be through a correlation, or it may be causal (Bond et al., 2004; Leung \& Bond, 2004; Leung et al., 2002). The belief statement, "Hard work leads to reward", for example, asserts that a causal relationship exists between "hard work" (labour) and "reward" (positive outcomes of the labour). It is therefore a general statement, as there are many forms of "hard work", just as there are many forms of "reward". Furthermore, it is not an attitude or value, as the respondent is neither assessing the desirability of "hard work", nor that of "reward". Hence, beliefs are different from values in the sense that the evaluative component of a value is general, while it is specific for a belief (Leung \& Bond, 2004). If the desirability pole of an evaluative belief becomes specific, it turns into a social axiom (Leung \& Bond, 2004; Leung et al., 2002). Axioms are therefore truth statements for the actor, as they do not assess desired goals (Leung \& Bond, 2004).

Social axioms are a newly added construct in the scientific assemblage and, even though research on social axioms is just beginning, it should justify its existence by improving our scientific reach. Social axioms, or people's beliefs about how the world functions, provide a different type of general orientation that may add to the predictive power of values (Bond et al., 2004). They also involve more than values, as they contribute to our understanding of social functioning by capturing important features of a culture that are different from those reflected by values. Social axioms have four functions: they promote important social goals, help people defend their selfesteem, express values, and help people understand the world (Kurman \& Ronen-Eilon, 2004; Leung et al., 2002).

According to Leung and Bond (2004), social axioms function like other constructs of individual differences, have their own nomological networks linking them to constructs such as values, and combine with these other psychological constructs to generate behaviour. Kurman and Ronen-Eilon (2004) therefore argue that social axioms are axiomatic beliefs that can guide behaviour in certain situations. 
Social axioms add predictive power over and above that provided by values, and therefore seem to offer a valuable new way for researchers to examine and explore various topics within the boundaries of social psychology. It can be asserted that values and social beliefs are two different domains of discourse, as very few, or even no, correlations are found between these two constructs. Hence, values are perceived as tapping self-aware motivational systems, while social axioms tap conceptions of the social context in which an actor must navigate his/her behaviour in negotiating outcomes from the world (Bond et al., 2004).

On the basis of qualitative research conducted in Hong Kong and Venezuela, as well as of Western literature on beliefs, Leung et al. (2002) identified a set of pan-cultural social axioms, and accordingly developed the Social Axiom Survey (SAS) to identify universal dimensions of culturally related social beliefs (Singelis et al., 2003) consisting of a five-factor/dimensional structure (Bond et al., 2004) of general beliefs (i.e., social axioms). This study was also replicated in the U.S.A., Japan and Germany, indicating that beliefs may be cultural general (Bond et al., 2004). These five factors or social axiom dimensions are labelled as social cynicism, reward for application, social complexity, fate control and spirituality (later re-labelled religiosity by Leung \& Bond, 2004). Social cynicism represents a negative assessment of human nature and social events ("Powerful people tend to exploit others"). Social complexity refers to the view that there are multiple solutions to social issues, and that the outcome of events is uncertain ("One's behaviours may be contrary to one's true feelings"). Reward for application refers to the position that the investment of human resources will lead to positive outcomes ("One will succeed if one really tries"). Fate control refers to the general belief that social events are influenced by impersonal, external forces ("Individual characteristics, such as appearance and birthday, affect one's fate"). Religiosity refers to the view that spiritual forces influence the human world and that religious institutions exert a positive effect on social outcomes ("Belief in a religion helps one understand the meaning of life") (Bond et al., 2004).

Unlike Hofstede's (1980) work on values, which focused on the cultural level (not the individual level), but similar to Schwartz's (1992) analysis of value types within cultural groups, the Social Axiom Survey of Leung et al. (2002) is pitched at the individual level and examines whether a stable factor structure of beliefs can be identified among individuals in different cultural groups. By following the same functionalist approach as Schwartz's (1992) logic for a universal structure of values, Leung and Bond (2004) propose that social axioms, like values, are instrumental for individuals to cope with a set of universal problems of survival and functioning. Social axioms are therefore an individual cognitive form of organisation, guidance and regulation that would facilitate adaptation to cultural environments characterised by certain reinforcement conditions. The structure underlying these axioms should also be identifiable in different cultural groups with diverse backgrounds. The commonality of the basic problems that all human beings face should therefore lead to the emergence of a pan-cultural structure of social axioms. Thus, social axioms, or general beliefs about the world, will most likely relate to social behaviours across contexts, actors, targets and time (Bond et al., 2004).

Kurman and Ronen-Eilon (2004) showed that social axioms are useful to characterise and understand cultures. Hence, social axioms describe basic, unique characteristics of a culture. However, it is necessary to verify the suggested universality of the existing SAS (Kurman \& Ronen-Eilon, 2004).

Theories that aspire to be universal must be tested in numerous culturally diverse samples (Schwartz\& Bilsky, 1990), irrespective of the fact that logistical factors prevent anyone from studying all cultures, which is required for a decisive conclusion of universality (Schwartz, 1992; Schwartz \& Bilsky, 1990). A pan-cultural factor analysis therefore includes all the subjects measured, ignoring their culture of origin. Furthermore, to build a truly universal theory that takes into account the influence of culture one must be able to link observed cultural differences to specific dimensions of culture that are hypothesised to have produced the differences (Leung \& Bond, 1989). Cross-cultural research also involves various steps that can generate random and systematic errors, for example, procedures followed in the administration of questionnaires (Van de Vijver \& Leung, 1997b), which jeopardise any real chance to identify a congruence structure, even if it does exist (Leung \& Bond, 2004).

Bond et al. (2004) have collected individual measures of belief taken from people in 41 nations (including South Africa), but in their analysis they treated the data at the culture level. Leung and Bond (2004) point out that one must bear in mind that individual-level and cultural-level analyses have no logical relationship with each other (e.g., Leung, 1989). Subsequent results and interpretations therefore refer to nations, and not to individuals. As a result, their aim was to discover the dimensions of social axioms that are identifiable at the cultural level and to compare these culture-level dimensions of social axioms with culture-level dimensions of values in order to evaluate their degree of overlap.

The objectives of this study were to investigate the replicability, construct equivalence, item bias and reliability of the Social Axioms Survey (SAS) in the South African Police Service (SAPS).

\section{RESEARCH DESIGN}

\section{Participants}

The study population consisted of applicants $(N=1535)$ who were recruited for the basic training programme for the SAPS. Applicants were tested in groups of 300 during September 2004. The sample included mainly blacks $(98 \%)$, along with three other groups (white, coloured and Asian). However, the three smaller groups were excluded due to small sample sizes. In terms of gender, $70 \%(n=1136)$ were men and $22 \%$ ( $n=336)$ were women (63 missing values). The black group consisted of the following cultural groups: Sepedi $(n=461)$, Sesotho $(n=196)$, Setswana $(n=206)$, SiSwati $(n=147)$, Isitsonga $(n=233)$, Tshivenda $(n=159)$, and IsiZulu $(n=131)$ (two missing values). The IsiXhosa and the IsiNdebele groups were excluded due to small sample sizes. The mean age of the sample group was 26 years $(S D=3,18)$. The entry-level qualification for the police is grade 12 , and for $95 \%$ of the sample group this was their highest qualification, while 3,7\% had a degree, diploma or a postgraduate qualification.

\section{Measuring instrument}

The Social Axioms Survey (SAS) instrument developed by Leung et al. (2002) was used in this study to determine if certain cultural beliefs were universal. The Survey on Social Beliefs Questionnaire consists of 60 social axiom statements (Leung et al., 2002). The SAS requires respondents to rate on a five-point Likert scale the degree to which they believe each of the 60 items to be true, ranging from 1 (strongly disbelieve) to 5 (strongly believe). Five social axiom factors are included: social cynicism (18 items), social complexity (12 items), reward for application (14 items), religiosity (eight items), and fate control (eight items). The variances that account for these five factors are $8,89 \%, 7,94 \%$, $5,22 \%, 4,09 \%$ and 3,28\% respectively (Leung et al., 2002). Internal consistencies (Cronbach coefficient alphas) reported by Bond et al. (2004) varied from 0,37 to 0,79 for social cynicism, 0,33 to 0,67 for social complexity, 0,33 to 0,72 for reward for application, 0,49 to 0,78 for religiosity, and 0,32 to 0,59 for fate control. 


\section{Procedure}

A standardised procedure was followed, and the SAS was part of a test battery that was administered by personnel of the Psychological Services of the SAPS. The test session lasted for three hours and included a break of 15 minutes. Computerreadable answer sheets were utilised for all the tests.

\section{Data analysis}

The statistical analysis was carried out with the help of the Comprehensive Exploratory Factor Analysis program (CEFA) of Browne, Cudeck, Tateneni and Mels (1998). The Statistica program Version 7.1 (Statsoft Inc., 2005) was used for the construct equivalence, item bias and reliability.

The fist step entailed the cleaning of the data set by replacing missing values with the mean value of the total group for a particular item. Variables that had more than $20 \%$ missing data were rejected from the final data file. The second step in data analysis utilised exploratory factor analysis with varimax (normalised) rotation. In this step, an indication of the number of factors that could be abstracted was obtained by utilising the eigenvalues greater than one criterion, as well as the scree plot. Target rotation was employed in the third step. A target matrix was specified and an oblique rotation was performed so as to minimise the sum of the squares of the differences of rotated elements and corresponding specified target elements.

In the fourth step, construct equivalence was addressed. This involved scale-level analyses and examined the similarity of the factors underlying the SAS. A scale-level analysis (construct equivalence) was conducted. A two-step procedure was used to examine construct equivalence, which is based on exploratory factor analysis. In the first step, the covariance matrices of all the cultural groups were combined (weighted by sample size) in order to create a single, pooled data matrix (cf. Muthén, 1991, 1994). Factors derived from this pooled covariance matrix defined the global solution, with which the factors obtained in the separate cultural groups were compared (after target rotation to the pooled solution). The agreement was evaluated by means of a factor congruence coefficient, Tucker's phi (Chan, Ho, Leung, Cha \& Yung, 1999; Van de Vijver \& Leung, 1997a, 1997b). Values above 0,90 were taken to point to essential agreement and values above 0,95 to very high agreement. High agreement implies that the factor loadings of the lower and higher levels are equal up to a multiplying constant. (The latter is needed to accommodate possible differences in the eigenvalues of factors for the language groups.)

In the fifth step, item bias was addressed. Item bias analysis was undertaken by utilising the analysis of variance of the SAS items. The item score was the dependent variable, while culture and score levels were the independent variables. A significant main effect of the culture group was taken to point to uniform bias, and a significant interaction of score level and culture interaction pointed to non-uniform bias. In the final step of the analysis, the reliability scores of the SAS factors for the different language groups were estimated.

\section{RESULTS}

Exploratory factor analysis utilising a varimax rotation was carried out on the cleaned data set, which included seven of the language groups. Eighteen factors with eigenvalues higher than one were extracted. These eighteen factors explained $47 \%$ of the total variance. However, the scree plot showed that five factors (which explained 23,28\%) of the total variance could be extracted (Factor 1=5,28; Factor $2=3,60$; Factor $3=2,10$; Factor $4=1,66$; and Factor $5=1,52$ ), as shown in Figure 1 .

Based on these results, an exploratory factor analysis (a fivefactor solution) with target rotation was carried out. This

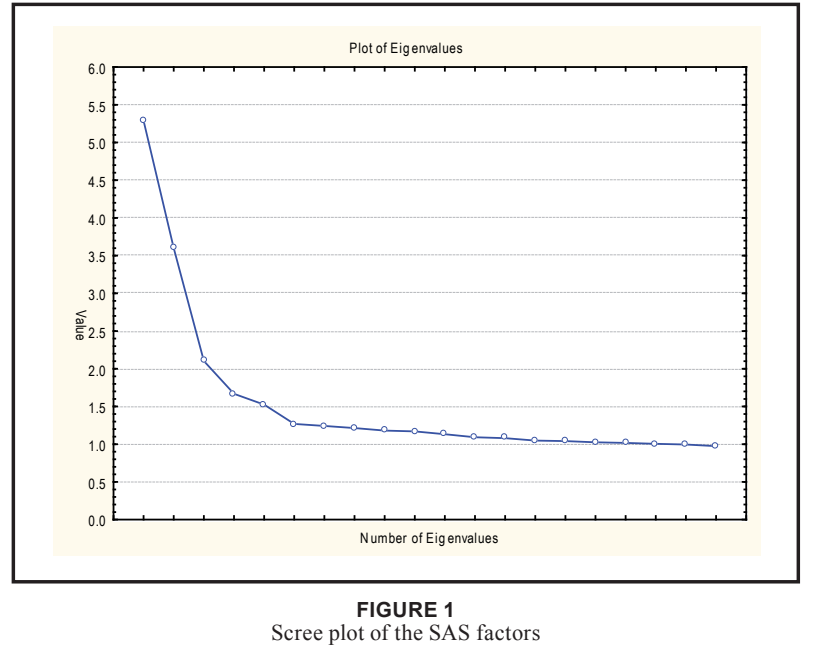

procedure assessed the extent to which the factor structure fitted the theoretical structure of Leung et al. (2002). Table 1 reports the target rotation results.

An analysis of the exploratory factor analysis utilising target rotation applied on all 60 items of the SAS revealed four interpretable factors (Factor 1 =Social Cynicism; Factor 2 = Reward for Application; Factor 4 = Fate Control; and Factor $5=$ Spirituality/Religiosity), congruent with the model of Leung et al. (2002). The third factor, Social Complexity, did not replicate. Item 18 had a loading of 0,42 but, according to Leung et al. (2002), belongs to Factor 2 (Reward for Application) and not to Factor 3 (Social Complexity), as seen in Table 1. The same applies to item 23, which belongs to Factor 3 (Social Complexity), and item 47, which belongs to Factor 1 (Social Cynicism) (Leung et al., 2002).

A confirmatory factor analysis, using items with loadings higher than 0,30 as a target, was subsequently carried out. The results are reported in Table 2. Social Cynicism reported 14 items, Reward for Application reported four items, Fate Control reported five items, and Spirituality/Religiosity reported four items that had loadings higher than 0,30 .

Table 3 shows the extent of agreement between the factors of the SAS derived from the pooled data and the factors in the seven culture groups. Values of Tucker's phi higher than 0,90 were found for all the culture groups. This provided a strong indication of the structural equivalence of the four factors underlying the performance of all the different groups distinguished.

In the analyses of variance of the item scores of the SAS (four factors), it was found that a few items showed a significant main effect of culture (uniform bias), or interaction of culture and score level (non-uniform bias). Out of the 27 items, 10 items turned out to be biased (37\%), which is a relatively small proportion. It can thus be concluded that item bias is not a major disturbance in the SAS in these language groups. The results are reported in Table 4.

Values of Cronbach's alpha of the scales in the seven language groups, based on the four factors of the SAS, are reported in Table 5.

Cronbach's alpha showed high levels of reliability, with values ranging from 0 to 1 . However, it is generally agreed that 0,70 is deemed a lower level of acceptability, and it may even decrease to 0,60 in exploratory research. Cronbach's alpha had a positive relationship to the number of items in the scale, implying that an increased number of items would increase the reliability 
TABLE 1

Exploratory factor analysis with target rotation on the 60 SAS items

\begin{tabular}{|c|c|c|c|c|c|}
\hline SAS ITEMS & $\begin{array}{l}\text { FACTOR 1: } \\
\text { Social } \\
\text { Cynicism }\end{array}$ & $\begin{array}{l}\text { FACTOR 2: } \\
\text { Reward for } \\
\text { Application }\end{array}$ & $\begin{array}{l}\text { FACTOR 3: } \\
\text { Social } \\
\text { Complexity }\end{array}$ & $\begin{array}{l}\text { FACTOR 4: } \\
\text { Fate } \\
\text { Control }\end{array}$ & $\begin{array}{l}\text { FACTOR 5: } \\
\text { Spirituality/ } \\
\text { Religiosity }\end{array}$ \\
\hline Religious faith contributes to good mental health. & $-0,07$ & 0,05 & $-0,02$ & 0,04 & 0,50 \\
\hline Caution helps avoid mistakes. & $-0,05$ & 0,20 & 0,17 & 0,02 & 0,12 \\
\hline Good luck follows if one survives a disaster. & 0,09 & 0,04 & 0,04 & 0,31 & 0,03 \\
\hline Human behaviour changes with the social context. & 0,03 & 0,10 & 0,21 & 0,14 & 0,07 \\
\hline Religion makes people escape from reality. & 0,22 & $-0,01$ & $-0,01$ & 0,14 & $-0,23$ \\
\hline People may have opposite behaviour on different occasions. & 0,03 & 0,23 & 0,19 & 0,03 & $-0,04$ \\
\hline One's appearance does not reflect one's character. & 0,09 & 0,18 & 0,10 & $-0,10$ & $-0,03$ \\
\hline Fate determines one's successes and failures. & $-0,01$ & 0,06 & 0,24 & 0,25 & 0,01 \\
\hline Religious people are more likely to maintain moral standards. & $-0,05$ & 0,01 & 0,08 & 0,06 & 0,46 \\
\hline Ghosts or spirits are people's fantasy. & 0,10 & $-0,07$ & 0,13 & 0,13 & $-0,03$ \\
\hline Individual effort makes little difference in the outcome. & 0,10 & 0,14 & $-0,16$ & 0,19 & $-0,02$ \\
\hline There is a supreme being controlling the universe. & $-0,01$ & $-0,02$ & 0,13 & 0,13 & 0,23 \\
\hline One who does not know how to plan his or her future will eventually fail. & 0,04 & 0,25 & $-0,02$ & 0,06 & 0,13 \\
\hline There are phenomena in the world that cannot be explained by science. & 0,05 & 0,08 & 0,31 & $-0,11$ & 0,01 \\
\hline Knowledge is necessary for success. & 0,03 & 0,45 & 0,07 & $-0,05$ & 0,12 \\
\hline Young people are impulsive and unreliable. & 0,40 & 0,05 & $-0,06$ & 0,03 & $-0,04$ \\
\hline It is rare to see a happy ending in real life. & 0,31 & 0,17 & $-0,18$ & 0,14 & $-0,09$ \\
\hline Mutual tolerance can lead to satisfactory human relationships. & $-0,04$ & 0,05 & 0,42 & 0,11 & 0,09 \\
\hline Individual characteristics, such as appearance and birthday, affect one's fate. & 0,14 & $-0,02$ & 0,02 & 0,31 & $-0,06$ \\
\hline Females need a better appearance than males. & 0,37 & 0,13 & $-0,16$ & 0,06 & 0,03 \\
\hline Adversity can be overcome by effort. & $-0,03$ & 0,13 & 0,24 & 0,061 & 0,11 \\
\hline Every problem has a solution. & $-0,03$ & 0,45 & 0,08 & 0,06 & $-0,02$ \\
\hline One has to deal with matters according to the specific circumstances. & $-0,03$ & 0,45 & 0,26 & 0,06 & $-0,02$ \\
\hline Competition brings about progress. & 0,05 & 0,22 & 0,17 & 0,08 & 0,01 \\
\hline There is usually only one way to solve a problem. & 0,17 & $-0,04$ & $-0,15$ & 0,20 & $-0,01$ \\
\hline Most disasters can be predicted. & 0,04 & $-0,06$ & $-0,02$ & 0,42 & 0,04 \\
\hline To deal with things in a flexible way leads to success. & $-0,08$ & 0,24 & 0,11 & 0,23 & 0,12 \\
\hline Old people are usually stubborn and biased. & 0,39 & 0,03 & $-0,06$ & 0,05 & $-0,09$ \\
\hline A person's talents are inborn. & 0,14 & 0,13 & 0,05 & 0,07 & 0,03 \\
\hline Good deeds will be rewarded, and bad deeds will be punished. & 0,07 & 0,20 & 0,09 & $-0,03$ & 0,21 \\
\hline One's behaviours may be contrary to his or her true feelings. & 0,04 & 0,16 & 0,15 & 0,13 & 0,05 \\
\hline There are certain ways to help us improve our luck and avoid unlucky things. & $-0,02$ & 0,12 & $-0,00$ & 0,34 & 0,10 \\
\hline One will succeed if one really tries. & 0,01 & 0,51 & 0,05 & $-0,04$ & 0,06 \\
\hline Failure is the beginning of success. & 0,11 & 0,03 & 0,20 & 0,03 & 0,05 \\
\hline Humility is dishonesty. & 0,19 & 0,00 & 0,06 & 0,18 & $-0,09$ \\
\hline To experience various life styles is a way to enjoy life. & 0,11 & 0,14 & $-0,01$ & 0,28 & 0,00 \\
\hline Religious beliefs lead to unscientific thinking. & 0,24 & $-0,08$ & 0,20 & 0,16 & $-0,15$ \\
\hline Social justice can be maintained if everyone cares about politics. & 0,15 & $-0,06$ & $-0,04$ & 0,26 & 0,10 \\
\hline Current losses are not necessarily bad for one's long-term future. & 0,06 & $-0,01$ & 0,11 & 0,10 & 0,05 \\
\hline To plan for possible mistakes will result in fewer obstacles, and will make things easier. & 0,09 & $-0,03$ & 0,28 & 0,19 & 0,03 \\
\hline Power and status make people arrogant. & 0,51 & $-0,02$ & 0,10 & $-0,13$ & 0,03 \\
\hline All things in the universe have been determined. & 0,12 & 0,02 & 0,00 & 0,09 & 0,28 \\
\hline Powerful people tend to exploit others. & 0,53 & 0,06 & 0,17 & $-0,25$ & 0,03 \\
\hline People will stop working hard after they secure a comfortable life. & 0,45 & 0,00 & $-0,01$ & $-0,09$ & 0,05 \\
\hline The various social institutions in society are biased towards the rich. & 0,40 & $-0,11$ & 0,02 & 0,01 & 0,12 \\
\hline Belief in a religion helps one understand the meaning of life, & 0,05 & 0,11 & $-0,09$ & $-0,05$ & 0,62 \\
\hline It is easier to succeed if one knows how to take short-cuts. & 0,19 & $-0,08$ & $-0,13$ & 0,31 & 0,02 \\
\hline Kind-hearted people are easily bullied. & 0,34 & $-0,07$ & 0,19 & $-0,07$ & 0,05 \\
\hline Old people are a burden on society. & 0,30 & $-0,02$ & $-0,28$ & 0,21 & $-0,05$ \\
\hline The just will eventually defeat the wicked. & 0,14 & $-0,12$ & 0,26 & 0,01 & 0,19 \\
\hline A modest person can make a good impression on people. & 0,09 & $-0,06$ & 0,12 & 0,13 & 0,23 \\
\hline Beliefs in a religion make people good citizens. & 0,09 & 0,05 & $-0,14$ & 0,04 & 0,56 \\
\hline People deeply in love are usually blind. & 0,41 & $-0,07$ & 0,12 & $-0,03$ & $-0,02$ \\
\hline Kind-hearted people usually suffer losses. & 0,50 & $-0,05$ & 0,143 & $-0,10$ & $-0,06$ \\
\hline To care about societal affairs only brings trouble for yourself. & 0,47 & $-0,02$ & $-0,13$ & $-0,01$ & $-0,11$ \\
\hline There are many ways for people to predict what will happen in the future. & 0,07 & $-0,05$ & $-0,04$ & 0,42 & 0,07 \\
\hline Hard-working people will achieve more in the end. & 0,07 & 0,48 & $-0,05$ & $-0,04$ & 0,08 \\
\hline $\begin{array}{l}\text { Significant achievements require one to show no concern for the means needed for } \\
\text { that achievement. }\end{array}$ & 0,20 & $-0,10$ & $-0,23$ & 0,18 & 0,01 \\
\hline Harsh laws can make people obey. & 0,26 & 0,03 & $-0,01$ & 0,06 & 0,01 \\
\hline Most people hope to be repaid after they help others. & 0,41 & 0,05 & $-0,02$ & $-0,10$ & $-0,02$ \\
\hline
\end{tabular}


TABLE 2

Confirmatory factor analysis on the SAS items (loadings $>0,30$ )

\begin{tabular}{|c|c|c|c|c|}
\hline SAS ITEMS & $\begin{array}{l}\text { FACTOR 1: } \\
\text { Social Cynicism }\end{array}$ & $\begin{array}{l}\text { FACTOR 2: } \\
\text { Reward for Application }\end{array}$ & $\begin{array}{l}\text { FACTOR 4: } \\
\text { Fate Control }\end{array}$ & $\begin{array}{l}\text { FACTOR 5: } \\
\text { Spirituality/ Religiosity }\end{array}$ \\
\hline Religious faith contributes to good mental health. & $-0,02$ & 0,03 & 0,07 & 0,49 \\
\hline Good luck follows if one survives a disaster. & 0,04 & 0,06 & 0,29 & 0,08 \\
\hline Religious people are more likely to maintain moral standards. & 0,02 & 0,03 & 0,02 & 0,46 \\
\hline Knowledge is necessary for success. & 0,03 & 0,47 & $-0,04$ & 0,10 \\
\hline Young people are impulsive and unreliable. & 0,29 & 0,03 & 0,19 & $-0,04$ \\
\hline It is rare to see a happy ending in real life. & 0,16 & 0,10 & 0,29 & $-0,11$ \\
\hline Individual characteristics, such as appearance and birthday, affect one's fate. & 0,06 & $-0,02$ & 0,33 & $-0,01$ \\
\hline Females need a better appearance than males. & 0,22 & 0,09 & 0,27 & $-0,03$ \\
\hline Every problem has a solution. & $-0,07$ & 0,52 & 0,04 & $-0,06$ \\
\hline Most disasters can be predicted. & $-0,07$ & $-0,04$ & 0,47 & 0,07 \\
\hline Old people are stubborn and biased. & 0,29 & 0,00 & 0,19 & $-0,12$ \\
\hline There are certain ways to help us improve our luck and avoid unlucky things. & $-0,08$ & 0,13 & 0,35 & 0,13 \\
\hline One will succeed if one really tries. & $-0,00$ & 0,56 & $-0,02$ & $-0,00$ \\
\hline Power and status make people arrogant. & 0,53 & $-0,00$ & $-0,07$ & 0,06 \\
\hline Powerful people tend to exploit others. & 0,59 & 0,09 & $-0,18$ & 0,08 \\
\hline People will stop working hard after they secure a comfortable life. & 0,40 & 0,01 & 0,05 & 0,00 \\
\hline The various social institutions in society are biased towards the rich. & 0,37 & $-0,06$ & 0,09 & 0,08 \\
\hline Beliefs in a religion helps one understand the meaning of life. & 0,09 & 0,09 & 0,01 & 0,60 \\
\hline Kind-hearted people are easily bullied. & 0,39 & $-0,02$ & $-0,05$ & 0,08 \\
\hline Old people are a heavy burden on society. & 0,12 & $-0,06$ & 0,38 & $-0,11$ \\
\hline Belief in a religion makes people good citizens. & 0,10 & 0,02 & 0,11 & 0,53 \\
\hline People deeply in love are usually blind. & 0,40 & $-0,01$ & 0,03 & 0,00 \\
\hline Kind-hearted people usually suffer losses. & 0,51 & $-0,03$ & $-0,02$ & $-0,02$ \\
\hline To care about societal affairs only brings trouble for yourself. & 0,35 & $-0,05$ & 0,18 & $-0,15$ \\
\hline There are many ways for people to predict what will happen in the future. & $-0,06$ & $-0,05$ & 0,52 & 0,10 \\
\hline Hard-working people will achieve more in the end. & 0,03 & 0,49 & 0,02 & 0,04 \\
\hline Most people hope to be repaid after they help others. & 0,35 & 0,04 & 0,04 & $-0,06$ \\
\hline
\end{tabular}

TABLE 3

Values of Tucker's phi for the factors of the SAS factor analysis for seven language groups

\begin{tabular}{llllllll}
\hline Scale & Zulu Sotho & Tswana & Swati & Tsonga & Venda & Pedi \\
\hline $\begin{array}{l}\text { Factor 1: } \\
\text { Social Cynicism }\end{array}$ & 0,98 & 0,98 & 0,99 & 0,97 & 0,98 & 0,98 & 0,99 \\
$\begin{array}{l}\text { Factor 2: } \\
\text { Reward for Application }\end{array}$ & 0,98 & 0,99 & 0,98 & 0,99 & 0,99 & 0,98 & 0,99 \\
$\begin{array}{l}\text { Factor 4: } \\
\text { Fate Control }\end{array}$ & 0,98 & 0,99 & 0,99 & 0,98 & 0,99 & 0,99 & 0,99 \\
$\begin{array}{l}\text { Factor 5: } \\
\text { Spirituality/Religiosity }\end{array}$ & 0,99 & 0,99 & 0,99 & 0,99 & 0,99 & 0,99 & 0,99 \\
\hline
\end{tabular}

value (Hair, Andersom, Tatham \& Black, 1998). Factor 1 (Social Cynicism) had 14 items, and values higher than 0,60 were found for all seven of the language groups. Factor 2 (Reward for Application) had four items and values higher than 0,60 were found for only the Zulu and Swati language groups. Factor 4 (Fate Control) had five items, but no values higher than 0,60 were found for any of the seven language groups. Factor 5 (Spirituality/Religiosity) had four items and values higher than 0,60 were found for the Sotho, Venda and Pedi language groups. Subsequent alphas were determined for the four factors utilising the whole group/study population $(N=1535)$. An acceptable alpha coefficient of 0,74 was found for Factor 1 (Social Cynicism). Neither of the remaining factors had an alpha of more than 0,60. An alpha of 0,57 was found for Factor 2 (Reward for Application), 0,52 for Factor 4 (Fate Control), and 0,38 for Factor 5 (Spirituality/Religiosity).

\section{DISCUSSION}

The objectives of this study were to investigate the replicability of the five-factor structure of the SAS in the SAPS, to examine the construct equivalence and item bias for different culture groups, and to assess the reliability of the SAS. An exploratory factor analysis utilising target rotation applied to all 60 items of the SAS revealed four interpretable factors (Social Cynicism,
TABLE 4

Items with small $(<0,01)$ effect size bias and significance of four SAS factors for the different language groups

\begin{tabular}{|c|c|c|}
\hline SCALES & UNIFORM BIAS & NON-UNIFORM BIAS \\
\hline \multicolumn{3}{|c|}{ Social Cynicism } \\
\hline Item 16 & 0,002 & 0,009 \\
\hline Item 17 & 0,000 & $0,010^{*}$ \\
\hline Item 20 & $0,023^{*}$ & $0,011^{*}$ \\
\hline Item 28 & $0,017^{*}$ & $0,013^{*}$ \\
\hline Item 41 & 0,002 & $0,012^{*}$ \\
\hline Item 43 & $0,010^{*}$ & 0,007 \\
\hline Item 44 & 0,006 & 0,007 \\
\hline Item 45 & 0,008 & 0,009 \\
\hline Item 48 & 0,003 & $0,013^{*}$ \\
\hline Item 49 & 0,007 & 0,007 \\
\hline Item 53 & 0,008 & 0,005 \\
\hline Item 54 & 0,002 & 0,006 \\
\hline Item 55 & 0,004 & 0,005 \\
\hline Item 60 & 0,004 & $0,014^{*}$ \\
\hline \multicolumn{3}{|c|}{ Reward Application } \\
\hline Item 15 & $0,011^{*}$ & $0,019^{*}$ \\
\hline Item 22 & $0,010^{*}$ & $0,011^{*}$ \\
\hline Item 33 & 0,004 & 0,009 \\
\hline Item 57 & 0,003 & $0,010^{*}$ \\
\hline \multicolumn{3}{|c|}{ Fate Control } \\
\hline Item 3 & 0,001 & 0,003 \\
\hline Item 19 & $0,010^{*}$ & 0,005 \\
\hline Item 26 & 0,006 & 0,005 \\
\hline Item 32 & 0,002 & 0,008 \\
\hline Item 56 & 0,003 & 0,006 \\
\hline \multicolumn{3}{|c|}{ Spirituality } \\
\hline Item 1 & 0,003 & 0,009 \\
\hline Item 9 & 0,002 & $0,010^{*}$ \\
\hline Item 46 & 0,000 & 0,004 \\
\hline Item 52 & 0,000 & 0,003 \\
\hline
\end{tabular}


TABLE 5

Values of Cronbach's alpha of the scales, based on the four factors of the SAS, in the seven language groups

\begin{tabular}{llllllll}
\hline Scale & Zulu & Sotho & Tswana & Swati & Tsonga & Venda & Pedi \\
\hline Factor 1: & $\mathbf{0 , 7 2}$ & $\mathbf{0 , 6 6}$ & $\mathbf{0 , 7 3}$ & $\mathbf{0 , 6 9}$ & $\mathbf{0 , 7 3}$ & $\mathbf{0 , 7 2}$ & $\mathbf{0 , 7 3}$ \\
$\begin{array}{l}\text { Social Cynicism } \\
\begin{array}{l}\text { Factor 2: } \\
\text { Reward for Application }\end{array}\end{array}$ & $\mathbf{0 , 6 9}$ & 0,57 & 0,53 & $\mathbf{0 , 7 7}$ & 0,57 & 0,57 & 0,59 \\
$\begin{array}{l}\text { Factor 4: } \\
\text { Fate Control }\end{array}$ & 0,48 & 0,53 & 0,54 & 0,54 & 0,49 & 0,53 & 0,50 \\
$\begin{array}{l}\text { Factor 5: } \\
\text { Spirituality/ Religiosity }\end{array}$ & $\mathbf{0 , 5 6}$ & 0,69 & 0,57 & 0,56 & 0,59 & $\mathbf{0 , 6 6}$ & $\mathbf{0 , 6 1}$ \\
\hline
\end{tabular}

Reward for Application, Fate Control, and Spirituality/ Religiosity), in correspondence with the model of Leung et al. (2002). The third factor, Social Complexity, did not replicate. Values of Tucker's phi higher than 0,90 were found for seven language groups (Zulu, Sotho, Tswana, Swati, Tsonga, Venda and Pedi), and analyses of variance found that item bias was not a major disturbance in the SAS. Lower levels of reliability were found for Cronbach's alpha.

An exploratory factor analysis (five-factor solution) utilising a target rotation was carried out on the 60 items of the SAS. This procedure assessed the extent to which the factor structure fitted the theoretical structure of Leung et al. (2002). Following from this, the first specific objective was to investigate the replicability of the five-factor structure of the SAS, as proposed by Leung et al. (2002), in the South African Police Service. The exploratory factor analysis, however, revealed only four interpretable factors (Factor 1 = Social Cynicism; Factor 2 = Reward for Application; Factor 4 = Fate Control; and Factor 5 = Spirituality/Religiosity), congruent with the model of Leung et al. (2002). The third factor, Social Complexity, did not replicate. Values of Tucker's phi higher than 0,90 were found for seven culture groups (Zulu, Sesotho, Setswana, Swati, Tsonga, Venda and Sepedi). This provided a strong indication of the construct equivalence of the four factors underlying the performance of all the different groups. Analyses of variance on the item scores of the SAS (four factors) found that bias was not a major disturbance in the SAS in these language groups.

Acceptable alpha values that ranged from 0,66 to 0,73 were found for Factor 1 (Social Cynicism) for all seven language groups. Only the Zulu and Swati language groups were found to have acceptable alpha values for Factor 2 (Reward for Application), of 0,69 and 0,77 respectively. The Sotho, Venda and Pedi language groups were found to have acceptable alpha values of 0,69, 0,66 and 0,61 for Factor 5 (Spirituality/Religiosity) respectively. No values higher than 0,60 were found for any of the seven language groups in relation to Factor 4 (Fate Control). Subsequent alphas were determined for the four factors utilising the whole group/study population $(N=1535)$. An acceptable alpha value of 0,74 was found for Factor 1 (Social Cynicism). No alpha values higher than 0,60 were found for any of the remaining factors. An alpha value of 0,57 was found for Factor 2 (Reward for Application); 0,52 for Factor 4 (Fate Control); and 0,38 for Factor 5 (Spirituality/Religiosity).

The number of items in each factor could be the reason why such low levels of reliability were reported. For example, Factor 1 (Social Cynicism) had 14 items, and alpha values that ranged from 0,66 to 0,73 were found for all seven of the language groups. However, Factor 2 (Reward for Application) had only four items, and this could be the reason why alpha values of 0,69 and 0,77 were only found for the Zulu and Swati language groups. The same applies to Factor 4 (Fate Control), which had only five items, and Factor 5 (Spirituality/Religiosity), with only four items. According to Hair et al. (1998), Cronbach's alpha has a positive relationship to the number of items in the scale, which implies that increasing the number of items will increase the reliability value. The number of items could therefore be the reason for the low alphas found for Factor 2 (Reward for
Application), Factor 4 (Fate Control) and Factor 5 (Spirituality/ Religiosity).

Inspection of the factor loadings revealed that items 18, 23 and 47 were problematic. These items loaded on different factors than expected. Item 18 loaded on Factor 3 (Social Complexity), but belonged to Factor 2 (Reward for Application), item 23 loaded on Factor 2 (Reward for Application), but belonged to Factor 3 (Social Complexity), and item 47 loaded on Factor 4 (Fate Control), but belonged to Factor 1 (Social Cynicism) (Leung et al., 2002).

Beliefs have been extensively used as variables of individual differences (Chen et al., 2006) to explain and predict social behaviour. People's beliefs about how the world functions (social axioms) provide a different type of general orientation (Bond et al., 2004) and contribute to our understanding of social functioning by capturing important features of a culture. The importance of this in a multicultural South African context, for example, is supported by Mbigi (1993), who argues that harmony can only be created when mutual values are experienced or accepted by the different groups. The cause of the problematic nature of these items can thus be explained by the possibility that different cultures add different meanings to these items, such as item 18 ("Mutual tolerance can lead to satisfactory human relationships"), item 23 ("One has to deal with matters according to specific circumstances"), and item 47 ("It is easier to succeed if one knows how to take short-cuts"). According to Census 2001 (Statistics South Africa, 2003), South Africa has 11 official language groups. Because English was not the first language of the majority $(99,4 \%)$ of the sample group, it is possible that these items were misunderstood. Researchers have shown that most imported tests are not ideally suitable for use in a multicultural society (such as South Africa), and that items in a questionnaire can be interpreted or understood differently by different cultures (Abrahams, 1996, 2002; Abrahams \& Mauer, 1999a, 1999b; Meiring, 2000; Spence, 1982; Tact, 1999; Taylor \& Boeyens, 1991). In addition, the English language used in tests is often too difficult to understand, even if English is the home language (Abrahams \& Mauer, 1999a, 1999b; Taylor, 2000; Wallis \& Brit, 2003).

Secondly, when comparing the sample sizes, the seven African language groups were relatively small, varying from 121 (Zulu) to 461 (Pedi). Factor analysis has limitations when applied to small samples.

According to Schwartz (1994c) and Triandis (1994), diversity is portrayed through different values and attitudes in different cultural groups. Just like individuals differ in their value priorities, different cultures also have different values and value priorities. Individuals therefore find themselves within a social environment inside a specific culture, with their own norms, language, systems and values (Smith \& Bond 1993; Triandis, 1994). Research has shown that nations, countries and other social categories tend to display distinct value profiles or patterns (Roe \& Ester, 1999). Following Hofstede (1980), Kluckhohn and Strodtbeck (1961), Rokeach (1973) and Schwartz (1999) argued that the cultural dimensions of values reflect the basic issues or problems that societies must face in order to regulate human activities. Williams (1970) added the view that cultural values represent implicit or explicit shared abstract ideas about what is good, right and desirable in a society. These cultural values are the base for the specific norms that tell people what is appropriate, or not appropriate, in various situations. Because priorities regarding cultural values are shared, role incumbents in social institutions can draw on them to select socially appropriate behaviour and to justify their behaviour choices to others (Schwartz, 1999).

This study had various limitations. Firstly, the sample sizes of the seven language groups (Pedi, Sotho, Tswana, Swati, Tsonga, Venda, and Zulu) were relatively small. Although the scores were 
standardised, the smaller sample size could have influenced the results. Secondly, only $0,6 \%$ of the participants spoke English as their home language. This could have contributed to misunderstanding of items and incorrect interpretations when the questionnaires were completed. Thirdly, the participants in this study were relatively young and mostly unemployed, which could affect the generalisation of findings.

\section{RECOMMENDATIONS}

Despite the limitations of this study, the present findings indicate that, with further research regarding the psychometric properties of the instrument, the SAS can be used effectively to measure beliefs/social axioms in a South African context.

Research in South Africa needs to focus on the prevalence of beliefs/social axioms among the different languages and cultural groups. To effectively use this instrument, and in order to enhance the application of the SAS in a multicultural and diverse South African context, it is proposed that the SAS be translated into various African languages, such as the seven language groups in this study. As translation issues do not form part of the particular focus of this study, I will only make some brief comments. According to Van de Vijver and Leung (1997b), the direct translation of an instrument/test is often regarded as the best option, as it is the easiest and the least cumbersome and also best preserves the possibility of a high level of equivalence across tests. An even better option is the adaptation of the instrument/test, thus to translate items with the aim of enhancing their appropriateness in the particular cultural context (Van de Vijver \& Leung, 1997b). This could possibly address the problem experienced with the exploratory factor analysis, where the third factor, namely Social Complexity, did not replicate. It could most likely also address the problematic item loadings, as found in items 18, 23 and 47.

To address the problems experienced with reliability, it is suggested that bigger samples are used. According to Hair et al. (1998), the relationships among alpha, sample size, effect size and power are quite complicated, and one must be aware that sample size can impact on the statistical test by either making it insensitive (at small sample sizes) or overly sensitive (at very large sample sizes).

It is also suggested that additional research be conducted to determine the validity and reliability of the instrument for other South African samples. Samples from different life and work settings might provide confidence that the study findings would be consistent across other, similar samples. Lastly, it is recommended that the samples in future studies include members of the Afrikaans- and English-speaking groups in order to compare the different language groups more effectively. Future research can then compare the African sample group with European and other Western samples.

\section{REFERENCES}

Abrahams, F. (1996). The cross-cultural comparability of the Sixteen Personality Factor Inventory (16PF). Unpublished doctoral thesis, University of Pretoria, Pretoria, South Africa.

Abrahams, F. (2002). Fair usage of the 16PF (SA 92) in South Africa: A response to C. H. Prinsloo \& I. Ebersohn. South African Journal of Psychology, 32, 58-61.

Abrahams, F. \& Mauer, K.F. (1999a). The comparability of the constructs of the 16PF in the South African context. Journal of Industrial Psychology, 25, 53-59.

Abrahams, F. \& Mauer, K.F. (1999b). Qualitative and statistical impacts of home language on responses to the items of the Sixteen Personality Factor Questionnaire (16PF) in South Africa. South African Journal of Psychology, 29, 76-86.

Bar-Tal, D. (1990). Group beliefs: A conception for analysing group structure, processes, and behavior. New York: Springer-Verlag.
Bem, D.J. (1970). Beliefs, attitudes, and human affairs. Belmont, CA: Brooks/Cole.

Bond, M.H., Leung, K., Au, A., Tong, K. \& ChemongesNielson, Z. (2004). Combining social axioms with values in predicting social behaviours. European Journal of Personality, 18, 177-191.

Bond, M.H., Leung. K., Au, A., Tong, K., Reimel de Carrasquel, S., Murakami, F., et al. (2004). Culture-level dimensions of social axioms and their correlates across 41 cultures. Journal of Cross-Cultural Psychology, 35, 548-570.

Brislin, R.W. (1994). Improving intercultural interaction: Modules for cross-cultural training programs. Thousand Oaks, CA: Sage.

Browne, M.W., Cudeck, R., Tateneni, K. \& Mels G. (1998). CEFA: Comprehensive exploratory factor analysis [WWW document and computer program]. Retrieved September 20, 2006 from the World Wide Web: http://quantrm2.psy.ohio-state. edu/browne/.

Chan, W., Ho, R.M., Leung, K., Cha, D.K.-S. \& Yung, Y.-F (1999). An alternative method for evaluating congruence coefficients with Procrustes rotation: A bootstrap procedure. Psychological Methods, 4, 378-402.

Chen, S.X., Bond, M.H. \& Cheung, F.M. (2006). Personality correlates of social axioms: Are beliefs nested within personality? Personality and Individual Differences, 40, 509519.

Festinger, L. (1957). A theory of cognitive dissonance. Stanford, CA: Stanford University Press.

Furnham, A. (1988). Lay theories. London: Pergamon Press.

Hair, J.F. Jr., Anderson, R.E, Tatham, R.L. \& Black, W.C. (1998). Multivariate data analysis (5th Ed.). Englewood Cliffs, NJ: Prentice Hall.

Heider, F. (1958). The psychology of interpersonal relations. New York: Wiley.

Hofstede, G. (1980). Culture's consequences: International differences in work-related values. Beverly Hills, CA: Sage.

Jahoda, G. (1988). Critical notes and reflections on "social representations". European Journal of Social Psychology, 18, 195-209.

Kelly, G. (1963). A theory of personal constructs. New York: W.W. Norton.

Kluckhohn, F. \& Strodbeck, F. (1961). Variation in value orientations Evanston, IL: Row, Peterson.

Kurman, J. \& Ronen-Eilon, C. (2004). Lack of knowledge of a culture's social axioms and adaptation difficulties among immigrants. Journal of Cross-Cultural Psychology, 35, 192208.

Leung, K. (1989). Cross-cultural differences: Individual-level vs. culture-level analysis. International Journal of Psychology, 24, 703-719.

Leung, K. \& Bond, M.H. (1989). On the empirical identification of dimensions for cross-cultural comparisons. Journal of Cross-Cultural Psychology, 20, 192-208.

Leung, K. \& Bond, M.H. (2004). Social axioms: A model of social beliefs in multi-cultural perspective. Advances in experimental social psychology (Vol. 36, pp. 119-197). San Diego, CA: Elsevier Academic Press.

Leung, K., Bond, M.H., Reimel de Carrasquel, S., Munoz, C., Hernandez, M., Murakami, F., et al. (2002). Social axioms: The search for universal dimensions of general beliefs about how the world functions. Journal of Cross-Cultural Psychology, 33, 286-302.

Lonner, W.J. \& Malpass, R.S. (1994). Psychology and culture. Boston, MA: Allyn \& Bacon.

Markus, H.R. \& Plaut, V.C. (2001). Social representations: Catching a good idea. In K. Deaux \& G. Philogene (Eds.), Representations of the social. Oxford, UK: Blackwell, pp.183189.

Mbigi, L. (1993). The spirit of African empowerment. People Dynamics, 11(3), 6 .

Meiring, D. (2000, June). Revisiting the cross-cultural comparability of the 16 Personality Factor Inventory (16PF) in the South African context. Paper presented at the Industrial Psychology Conference (incorporating the Psychometrics Conference), Pretoria, South Africa. 
Muthén, B.O. (1991). Multilevel factor analysis of class and student achievement components. Journal of Educational Measurement, 28, 338-354.

Muthén, B.O. (1994). Multilevel covariance structure analysis. Sociological Methods \& Research, 22, 376-398.

Roe, R.A. \& Ester, P. (1999). Values and work: Empirical findings and theoretical perspective. Applied Psychology: An International Review, 48(1), 1-21.

Rokeach, M. (1973). The nature of human values. New York: Free Press.

Schwartz, S.H. (1992). Universals in the content and structure of values: Theory and empirical tests in 20 countries. In M. Zanna (Ed.), Advances in experimental social psychology (Vol. 25, pp. 1-65). New York: Academic Press.

Schwartz, S.H. (1994a). Packet for participation in cross-cultural research on values. Department of Psychology, The Hebrew University.

Schwartz, S. H. (1994b). Are there universal aspects in the content and structure of values? Journal of Social Issues, 50, 19-45.

Schwartz, S.H. (1994c). Beyond individualism/collectivism: New cultural dimensions of values. In U. Kim, H.C. Triandis, S.C. Kagiticibasi, G. Choi \& G. Yoon (Eds.), Individualism and collectivism: Theory, method and applications. London: Sage, pp. 85-119.

Schwartz, S.H. (1999). A theory of cultural values and some implications for work. Applied Psychology: An International Review, 48, 23-47.

Schwartz, S.H. \& Bilsky, W. (1990). Toward a theory of the universal content and structure of values: Extensions and cross-cultural replications. Journal of Personality and Social Psychology, 58, 878-891.

Schwartz, S.H., Melech, G., Lehmann, A., Burgess, S., Harris, M. \& Owens, V. (2001). Extending the cross-cultural validity of the theory of basic human values with a different method of measure. Journal of Cross-Cultural Psychology, 32, 519542.

Singelis, T.M., Hubbard, C., Her, S. \& An, S. (2003). Convergent validation of the social axiom survey. Personality and Individual Differences, 34, 269-282.
Smith, P.B. \& Bond, M.H. (1993). Social psychology across cultures. Cambridge: Harvester Wheatsleaf, University Press.

Spence, B.A. (1982). A psychological investigation into the characteristics of black guidance teachers. Unpublished Master's thesis, University of Pretoria, Pretoria, South Africa.

Statistics South Africa. (2003). Census 2001: Persons. Retrieved January 3, 2006 from http://www.statssa. gov.za/specialprojects/census2001/census/database/ census\%202001/provincial\%20level/persons/persons.asp.

StatSoft Inc. (2005). Statistica (data analysis software system) Version 7.1. Retrieved September 20, 2006, from the World Wide Web: http://www.statsoft.com.

Tact, H. (1999). The cross-cultural validity and compatibility of the Sixteen Personality Factor Questionnaire. Unpublished Master's thesis, University of Pretoria, Pretoria, South Africa.

Taylor, I.A. (2000). The construct comparability of the NEO-PI-R questionnaire for black and white employees. Unpublished doctoral dissertation. University of the Free State, Bloemfontein, South Africa.

Taylor, T.R. \& Boeyens, J.C.A. (1991). A comparison of black and white responses to the South African Personality Questionnaire. Pretoria: Human Sciences Research Council.

Triandis, H.C. (1994). Cultural and social behavior. New York: McGraw-Hill.

Van de Vijver, A.J.R. \& Leung, K. (1997a). Methods and data analysis of comparative research. In J.W. Berry, Y.H. Poortinga \& J. Pandey (Eds.), Handbook of cross-cultural psychology (2nd Ed.), volume 1, pp257-300, Boston, MA: Allyn \& Bacon.

Van de Vijver, F.J.R. \& Leung, K. (1997b). Methods and data analysis for cross-cultural research. Newbury Park, CA: Sage.

Wallis, T. \& Brit, M. (2003). A comparison of native and nonnative English-speaking groups understanding of the vocabulary containing in the $16 \mathrm{PF}$ (SA92). South African Journal of Psychology, 33, 182-190.

Williams, R.M. (1970). American society: A sociological interpretation (3rd Ed.). New York: Knopf. 